\title{
Sex-Ratio Imbalance: Impending Feminity
}

\author{
Dr. Pragyan Mohanty \\ Dept of Women's Studies, Ravenshaw University, Cuttack, Odisha, India
}

\begin{abstract}
This paper tries to bring forth the very serious problem of sex selective abortions in India in general and odisha in particular. The very serious threat to the lives of the girl child from the mother's womb is addressed in this paper as it is the most heinous of al crimes against the female gender. Discrimination against the girl child and the hold of patriarchy is clearly visible in our society. Certain interviews from women belonging to various age groups and socio-economic status are taken to understand this issue better. The PNDT Act is examined thoroughly as despite this measures sex secleting abortion which leads to the very serious problem of Sex-ratio imbalance goes unabated.
\end{abstract}

Key words: Sex-ratio, Feticide, patriarchy, Violence against women, Discriminations.

\section{Introduction}

From prehistoric times gender roles were prevalent like men went to hunt and women were mostly gathers and did house hold chores. With changing times no role reversal is observed within the two genders even though the female gender has taken work out side the realms of household and domesticity. Gender as a term explains the biological differences between two sects of individuals, and due to the female anatomy women are assumed to be the weaker sex. Unless this assumption, this predisposition of ideas changes there can be no equality between the two genders. The biological disposition in reality dose not make us superior or inferior but the social tags of feminity and masculinity, the roles, duties ,expectations manifests this idea of gender inequality in us. Despite efforts to neutralize this situation it is difficult for not only men but women as well to give equal status to the female gender regardless of their biological differences and preconceived notions of roles within the society.

Gender inequality leads to gender imbalance which was always a threat in our society as the preference to have a male child took precedence. But this threat has alarmingly risen in Asian countries like china and India and even in other parts of the globe. This gender imbalance is observed when the Gender ratio of newborns is compared. Gender ratio of newborns refers to the ratio of male newborns which shows a higher rise than normal in comparison to female ones.

The accepted norm for of sex ratio is number of females per 1000 males but an unusual discrepancy is observed especially in our society. (Source: Census). If we view the statistics we find that Sex ratio in India was 972 in 1901 but has come down to 933 in 2001. The sex ratio in odisha was 1037 in 1901 but in the year 2001 it was 972. The survival of the girl child and even the female fetus is at great risk leading to gender imbalance.

Due to the wide spread practice of sex selective abortions the female fetus is at risk even in the safest place that is the mother's womb. If born the female infant is killed by drowning, suffocation, poisoning, starvation or abandonment. The ones that are kept by families are mistreated and not even given proper food and care and often these female infants die due to inadequate food.

The child sex ratio (0-6 years) is the number of female in the age group of 0-6 years to 1000maless, in India the CSR has shown a decline of 18 points between the census of $1991-2001$ as in 1901 the CSR was 945 it was 927 in 2001. In odisha the CSR has seen a steady decline as in 1991 census it was 967 and in 2001 census it was 950 a decline by 50 points. According to the census only Nabrangpur district has more number of girls than boy's 1002 girl child per 1000 boys.

The latest data shows that Sex ratio is declining markedly in 26 districts including 12 tribal and 14 costal districts. Despite high rate of literacy decline rate is equally high in districts like Dhenkanal-55, Nayagarh-53, and Anugul-53. The sex ratio decline in developed, litrate and aware cities like Cuttack is by 26 points. Sex ratio has increased in only three districts i.e. Jagatsinghpur-3, Baudh-9 and Nuapada-2 and the district of Ganjam remains unchanged.

This imbalance could be due to factors like patriarchal social system, the culturally strong preference of male child, nuclearization of families' especially in urban areas, migration, inadequate social security to women, availability in gender-distinguishing medical techniques, misconceptions like less number of women greater demand hence their status will improve, it is safer to eliminate daughters than let them suffer dowry and atrocities, and it is accepted to have sex selective abortion if you have two or more daughters. 
The consequences or outcome of such imbalance could be devastating like, Rise in atrocities against women, Rise in number of bachelors, Rise in sex outside marriage, Strengthen patriarchal system, Unequal distribution of labor, Rise in domestic violence and many such inequalities that will render women a very negative position in the society and push her further down the ladder. These gender imbalances will not only detoriate the status of women but create unrest in the ecological and sociological equilibrium of the world.

\subsection{Major Eradication Procedure-}

Major eradication procedures for this gender imbalance needs to be implemented immediately, although the government of India has already initiated measures like the"PNDT ACT in 1994, provides for the regulation of the use of prenatal diagnostic techniques for the purpose of detecting genetic or metabolic disorders or certain chromosomal abnormalities or congenital and for the prevention malformations or sexlinked disorders and for the prevention of misuse of such techniques for the purpose of prenatal sex determination leading to female foeticide and for matters connected therewith or incidental thereto" this act was one of the strongest eradication procedure as it tried to put a stop on the misuse of technology to create gender imbalance. As technology had become a tool to propagate and practice patriarchy in our society. But due to the inadequacies in policy implementation the PNDT ACT was violated despite being implemented since 1994.

Another act to be violated and misused is the Medical Termination of Pregnancy (MTP) Act-1974 which permits abortaion under certain conditions but is continually used for sex selective abortions.

The PNDT Act was amended in 2003 following a public litigation (PIL) filed in 2000 to regulate technology and arrest the decline in sex ratio. The amended act was called "The Preconception and Prenatal Diagnostic Techniques (prohibition of sex selection) Act” (PC AND PNDT ACT) not only prohibits determination and disclosure of the sex of the fetus but also bans advertisements related to preconception and prenatal discrimination of sex. All the technologies of sex determination, including the new chromosomal separation technique have also come under the gambit of this act. This Act provides- prohibition of sex selection before and after conception, regulation of prenatal diagnostic techniques for diction of genetic abnormalities, prevention of misuse of such techniques foe sex selection before and after conception, prohibition of advertisement of any techniques of sex selection as well as sex determination, prohibition on sale of ultra sound machines to persons not registered under this act.Despite these measures there is still a gross decline in sex ratio.

Female fetuses are still aborted and the bodies of female infants are still found in dustbins and dumped in paper bags in stations and bus stands. Technology is still misused, the female fetus and infants are still in danger and violence against women goes on unabated.

\section{Study Area Back Ground}

To find some answers to this practice of sex selective abortions, infanticide and violence against women certain qualitative interviews have been taken from the twin cities of Cuttack and Bhubaneswar, odisha.

Having both educated and illiterate masses from well to do house holds to slums and migrant workers and having multitude cultures and traditional practices, the twin cities offers a perfect background to study this problem. As both the cities according to the census is at number 12 out of the total number of districts out of thirty that has a sex ratio below 950 . The temple city of Odisha, Bhubaneswar is situated at 20degrees $15 \mathrm{~N}$ latitude and 85degree50E'longitude at about $25 \mathrm{kms}$ from Cuttack. This happens to be the oldest city of Odisha estimated to be two thousand and six hundred years old. 'TOSHALI' as it was previously known in its ancient records has about 7.000 temples, the architectural grandeur of which dates back to the $6^{\text {th }}$ to $15^{\text {th }}$ century A.D.Bhubaneswar consists of two parts, the old city and the new capitol. The railway track running across the city serves as a demarcation line between the old and new city. The old city contains splendid specifier of 'Kalinga Architecture' spanning twenty-five centuries history, depicting the grace, joy and rhythm of life. According to 2001 census the total population is $6.53,00$ (aprox). The density of population is about 4500 per sq. km.

As per the census the population of Bhubaneswar in 2011 is 837,737 of which male and female are 445,233 and 392,504 respectively, the sex ratio of Bhubaneswar city is 822 per 1000males. And despite the high literacy rate of 710,243 of which 388,164 are males and 322,079 are females. The average literacy rate of city is 93.15 percent of which male literacy rate was 95.69 percent and female literacy rate was 90.26 percent. According to the Telegraph (Dt.18 ${ }^{\text {th }}$ April 2012)

Cuttack is the former capital and the largest city of state of Odisha. It is located about $28 \mathrm{~km}$. to the north east of Bhubaneswar, the capital of Odisha. Cuttack district is one of the 30 districts in Odisha state in eastern Indi. Its administrative headquarters is the city of Cuttack. As of 2011, it is the second most populous district of Odisha, after Ganjam.

In 2011, Cuttack had population of 2,618,708 of which male and female were 1,339,153 and 1,279,555 respectively. The district has population density of 666 inhabitants per square kilometre. Its population growth rate over the decade $2001-2011$ was $11.86 \%$. 
According to the latest census report, population of Cuttack in 2011 is 606,007 of which male and female are 303,530 percent and 302,477 percent respectively. The sex ratio of Cuttack city is 997 per 1000 males.

Despite the high literacy rate of 508,188 of which 272,257 are males while 235,931 are females. The average literacy rate of Cuttack city is 91.17 percent of which male and female literacy rate was 97.87 percent and 84.48 percent respectively.

\section{III. case Studies}

It is difficult to understand the mindset of people as they have different backgrounds, customs and beliefs thus, this is a modest attempt to interview women from various walks of life and try to understand the reason behind this gender imbalance.

Mrs.Ranjana Senapati, age 51, educational qualification M.A, Occupation Demonstrator in S.B Women's College, belonging to Shakebazar, Cuttack. She has one son and one daughter. Traditionally, there is a belief that only men can perform the traditional ancestor cult and the major causes of discrimination against the female child have been the son preference rooted in a patriarchal society and the prevalence of dowry. Their lack of education, low financial productivity, and negligible presence in high-profile professions and positions has only added to the devaluation of females. The female child is increasingly seen as a high input and no output investment, reducing the child to little more than a commodity in the eyes of society. This devaluation of females leads to primal cause of various atrocities against women.

P.Tulsi, age 46, daily, Occupation wage laborer, belonging to Patapole Slum, Cuttack. Educational Qualification-Illitratre.She has one daughter and two sons. She got married when she was 16 years of age and has never been to school, she is originally from Andhra Pradesh. Her family came to odisha when she was 10 years old. She faced many difficulties being a woman the worse was violence by her husband. She was expected to give birth to a son as her another in law has four sons and one daughter who died at birth. So I was also to follow the legacy of sons thankfully I had a son first, eventhough I like my daughter but there is a strong son preference in the community I live in. and I am glad I have two sons as they help me financially, my daughter was also earning but she absconded with some one and is now married. I prefer having son's as I cannot look after a daughter as I am out working all day a daughter needs safety and guidance that I couldn't provide and look what my daughter did. Our society will need a very long time to change.

Santivena Sethi, age 48, house wife, belonging to Nayapalli, Bhubaneswar, educational qualificationB.A.She has three daughters. I feel there was gender preference in our society and still is and sex selective abortions, rather it is more pronounced in our society today due to advanced technology. Having three daughters I also wanted a son as this is embedded in us by our culture and society. Son also gives last rites to parents so the need for son is more than daughters. The rise in female infanticide and feticide could be due to factors like nuclerialization of families where a daughter's safety is of constant concern.

R.Nagamani, age 23, house wife, belonging to Patapole Slum, Cuttack, Educational Qualification- STD VIII, She has one son and one daughter. At a very early age I was married and couldn't continue my education and I think this is the main reason for all these problems of female infanticide. I was also under pressure for a son by my in laws as my husband is the only son and they need a heir and a son is a must to perform the last rites of parents and grand parents. My in laws are not happy as my second child is a daughter. I don't mind a daughter and is very happy but I worry about her as her grand parents and father might not love her like they love my son.

Miss Susmita Das, age 23, educational qualification M.A, Occupation Student, Belonging to Shakebazar, Cuttack. The most telling indicator of women's devalued position in society is the condemned sexselective abortions which results grave forms of discrimination against women. While education and good legal backing can put girls on a firm footing, a change in attitude should happen in every home. Every mother should stand up for her daughter. And every woman should have a feminist perspective and consider herself equal with men to preserve her position in the society for which she deserves. Then only she can break the evil belief of traditional patriarchy system and can balance the sex ratio to bring harmony in the society.

Gouri Barik, age 30, belonging to Laxmisagar slum, household laborer, unmarried. Dowry and dowry related death is scaring parents to have girl children. I would also want a son as I can protect him better than a girl and I don't have to worry about dowry as my parents are worrying about mine. Even though I am earning I have become a burden for my family as I am not married yet. There are no such issues where my brothers are concerned. The sons lead a charmed life in our society.

Y.Durga, age 20, educational qualification- std-VI, house wife, Belongign to Patapole Slum, Cuttack. I was recently married and have just conceived. My in laws and even my parents and husband already believe that it will be a boy. Although I want a girl, the preference for a son in our village and community is very strong due to dowry and violence against women. My mother had a lot of difficulty in arranging dowry for my marriage. I 
wish dowry and problems girls face like eve-teasing, molestation ect would disappear so there will be no more abortions of girl children.

Mrs.Lipsa Das, age 22, educational qualification B.A, Occupation Student, belonging to Cuttack Chandi, Cuttack. She has one daughter. I don't believe in any difference between the two genders, I have been brought up in my family in a very gender equal way. There was no compromise in my upbringing. Education I believe plays a very important role for the betterment of women. I am married in a Christian family and I see no fear of dowry for my sister in laws but security for women is a major concern for every culture. The latest statistics definitely show a high increase in female infanticide and could be due to dowry threat and other atrocities against women. But killing girl children is not the answer to these problems in our society.

Bhanu Devi, age 34, Daily wage laborer belonging to Bharatpur Slum, Bhubaneswar. She has one daughter. I have one daughter and am constantly worried about her marriage and dowry. But she is not a burden for me as she can also earn a livelihood like sons. Until violence and dowry deaths are not eradicated from our society our daughters will never be safe.

Drishanka Tyutisikha, age 26 yrs, lecturer in women's studies, Adasppur college, belonging to Cuttack road, Bhubaneswar. There is a strong preference for a male child in our society regardless of educational attainment. As even in educated masses there is a preference for a son. Although the pressure of our culture for dowry is the main reason for sex selective abortions but killing girl children after birth or in the mothers womb is not going to solve the problem rather greater problems will emerge from this like gender imbalance in the future.

R.Laxmi, age 42, house hold laborer, belonging to Laxmisgar slum. She has three daughters and one son. The preference for son is there in our society and in every family. I tried to have a son and kept on trying until I had a son. The pressure from my family for a son was very strong as they are from the village and a son is a must for offering last rites and I am glad that I have a son. Even though my daughters are earning but I worry about there safety and dowry, even after there marriage I will still worry about there safety because of dowry related torture. It is better to be a male child than a female child in this type of society.

Anahuta Priyadarshini, age 26, educational qualification-M.A, occupation teacher, belonging to Santosh Vihar,

Laxmisagar, Bhubaneswar. The atrocities against women are causing great concern in our society and the rising cases of female infanticide is perhaps the outcome of these atrocietes.I would like to have a daughter as daughters are no less an asset than sons and despite the detoriating conditions of women in our society I think sex selective abortions are not the answer but creating awareness and a safe environment for women are necessary.

\section{Conclusion}

The above data especially from the qualitative interview presents a clear picture of discrimination against the female gender in our society. It has become an every day affair to read in the newspaper of female infants found in dustbins and on railway stations wrapped in plastic bags. The misuse of technology which is for the detection of abnormalities or problems in fetuses before birth is misused rampantly by both the educated class and illiterate class for the sole purpose of having a male child. The reasons for this is manifold that varies from blind beliefs to social customs that degrades the female gender like Dowry and the pressure of poverty that makes the daughters a liability especially in the rural areas and of course the hard core fact that female fetuses are to be killed in the mothers womb till the conception of a male fetus.

The case studies reveal that education is the key to stop such practices and hence the spread of education especially in rural areas is of immense importance. And the regression of practices as Dowry is also of vital importance.

Certain actions have to be initiated for to solve this problem like, overall attitudinal change towards the girl child, discard of practices such as dowry, strict implementation of the PNDT ACT, Convictions on the cases against ultra sound clinics, Gendersentisation programmes especially at rural levels, income opportunities for girls and women. By implementing a few of these smaller changes a greater change is bound to come.

\section{Research reports}

\section{Reference}

[1] Sansristi, Bhubaneswar, Withering gender equity-Action research on declining child sex ratio in Orissa, 6-7, 2009\&2010

[2] Women's study programme, Ravenshaw University, Cuttack, odisha, India, Women in old age: Problems and prospects, 25, 2012

Books

[3] Das Pragyan, Status of unwed mothers in odisha: An analysis, (lap Lambert publishing, Germany) 167,2012 